\title{
Detecting the fingerprints of observed climate change on surface ozone variability
}

\author{
Owen R. Cooper \\ Cooperative Institute for Research in Environmental Sciences, University of Colorado, Boulder, USA \\ NOAA Earth System Research Laboratory, Boulder, USA
}

At the surface, tropospheric ozone is an air pollutant that adversely impacts human health, natural vegetation and crop yield and quality. This important trace gas also plays key roles as a greenhouse gas, and as the primary source of the hydroxyl $(\mathrm{OH})$ radical, which determines the lifetime of many other trace gases in the atmosphere. Tropospheric ozone has a variety of sources including photochemical production from anthropogenic and naturally occurring precursor gases, and transport from the stratosphere. As a result of its high reactivity and its wide range of sources, ozone's lifetime can vary from minutes in the polluted boundary layer to several weeks in the mid- and upper troposphere.

Ozone is so variable in the atmosphere that scientists have difficulty maintaining an up-to-date assessment of its global distribution and trends, an ongoing endeavor that is complicated by additional chemistry and meteorological challenges $[1,2]$. In terms of chemistry, the primary emissions regions of ozone precursor gases have continually shifted over the past 30 years from North America and Europe to Asia [3], and the global ozone production hot-spots have shifted accordingly. A further complication arises from ozone's non-linear production rate, with lower ozone production efficiency at high latitudes and greater production efficiency in the tropics, precisely where precursor emissions are rapidly increasing.

In terms of meteorology, shifting weather patterns can modulate ozone at a given location on time scales of hours, days, months, or even years. Previous research has shown that ozone concentrations experience dipole fluctuations across the tropical Pacific Ocean on a rough time scale of 5 years, in response to El Niño/Southern Oscillation (ENSO) [4]; ozone also fluctuates on multi-year time scales at Mauna Loa Observatory (3.4 km above sea level) in the tropical North Pacific Ocean, due to the PacificNorth American pattern [5]. These types of ozone fluctuations are caused by cyclical climate variability which occurs on relatively short time scales compared to long-term climate change. Because ozone changes associated with climate variability can be as large as those caused by anthropogenic emissions, ozone records longer than 20 years are necessary to distinguish the influence of human activity from the noise of climate variability [6]. On longer time scales, climate change is expected to strengthen the Brewer-Dobson circulation and the mid-latitude transport of stratospheric ozone into the troposphere, and to strengthen air mass stagnation in association with surface anticyclones, which would lead to enhanced ozone concentrations near the surface [7].

A new study by Lu et al. [8], appearing in Science Bulletin, explores a new aspect of the impact of climate change on surface ozone trends. To date, studies of the impacts of climate change on tropospheric ozone have focused on future scenarios in a much warmer world, as relatively strong temperature increases are required for the chemistry-climate models to detect an impact on ozone trends. However, Lu et al. [8] argue that there is now evidence that present-day levels of climate change have already contributed to a widening of the Hadley circulation [9], which has impacted surface ozone levels. Given the difficulty of distinguishing between the impacts of anthropogenic emissions, climate variability and climate change on long-term ozone trends, the authors focused their study on remote sites in the Southern Hemisphere, which experience far less impact from anthropogenic emissions than similar sites in the Northern Hemisphere. As shown in Figure 1, present-day ozone monitoring at rural locations is very limited in the Southern Hemisphere (22 available sites) compared to the Northern Hemisphere (1163 available sites) [1]. Despite the limited ozone monitoring in the Southern Hemisphere, the authors were able to take advantage of several long-term observational records of ozone, as measured by remote surface ozone monitors, ozonesondes (weather balloons), and satellites.

The study is centered on the premise that the Southern Hemisphere branch of the Hadley circulation has widened over the period 1979-2016, at the rate of about $1^{\circ}$ latitude per decade, as 
demonstrated by seven global reanalysis data sets [9]. This widening is partly attributable to anthropogenic climate change. Lu et al. [8] used a global chemical transport model to explore the impact of Hadley circulation widening on tropospheric ozone across the Southern Hemisphere. They learned that the observed ozone increase cannot be explained by increases of anthropogenic emissions of ozone precursors. Rather, the Hadley circulation widening has changed transport patterns across Southern midand high latitudes and it has also shifted the flux of ozone from the stratosphere to higher latitudes. The shifting transport patterns and their redistribution of ozone precursor gases has produced an environment at mid- and high latitudes that is more conducive to photochemical ozone production.

Lu et al. [8] have made the case that observed and modeled changes of the Southern Hemisphere circulation can be partly attributed to anthropogenic climate change, and these circulation changes can affect long-term ozone trends. Looking forward, future work could explore the impacts of climate change on other aspects of ozone production and loss. For example, surface ozone concentrations are influenced by contact with the Earth's surface, especially in the presence of vegetation which acts as an ozone sink. On the other hand, ozone is not lost to water and ice surfaces. As land cover changes with a warming climate we can expect that ozone loss at the surface will also change, especially in polar regions where semi-permanent snow and ice on land transitions to soil and vegetation. Recent developments in land cover monitoring and data assimilation make this type of analysis possible [10]. Continued model development and data assimilation, and continuing climate change over the next decade, will lead to improved understanding of the global distribution and trends of tropospheric ozone, and the influence of circulation changes.

\section{References}

[1] Schultz, M. G., et al. (2017), Tropospheric Ozone Assessment Report: Database and metrics data of global surface ozone observations, Elem Sci. Anth, 5:58, DOI: http://doi.org/10.1525/elementa.244

[2] Gaudel, A., et al. (2018), Tropospheric Ozone Assessment Report: Present-day distribution and trends of tropospheric ozone relevant to climate and global atmospheric chemistry model evaluation, Elem. Sci. Anth., 6(1):39, DOI: https://doi.org/10.1525/elementa.291

[3] Zhang, Y., O. R. Cooper, A. Gaudel, A. M. Thompson, P. Nédélec, S.-Y. Ogino and J. J. West (2016), Tropospheric ozone change from 1980 to 2010 dominated by equatorward redistribution of emissions, Nature Geoscience, 9(12), p.875, doi: 10.1038/NGEO2827.

[4] Oman, L. D., J. R. Ziemke, A. R. Douglass, D. W. Waugh, C. Lang, J. M. Rodriguez, and J. E. Nielsen (2011), The response of tropical tropospheric ozone to ENSO", Geophys. Res. Lett., 38, L13706, doi:10.1029/2011GL047865.

[5] Lin, M., L.W. Horowitz, S. J. Oltmans, A. M. Fiore and S. Fan (2014), Tropospheric ozone trends at Mauna Loa Observatory tied to decadal climate variability, Nature Geoscience, 7, 136-143 doi:10.1038/ngeo2066.

[6] Barnes, E. A., A. M. Fiore, and L. W. Horowitz (2016), Detection of trends in surface ozone in the presence of climate variability, J. Geophys. Res. Atmos., 121, 6112-6129, doi:10.1002/2015JD024397.

[7] Jacob, DJ and Winner, DA. 2009. Effect of climate change on air quality. Atmospheric Environment, 43(1): 51-63. DOI: https://doi.org/10.1016/j.atmosenv.2008.09.051

[8] Lu, X., Zhang, L., Zhao, Y., Jacob, D.J., Hu, Y., Hu, L., Gao, M., Liu, X., Petropavlovskikh, I., McClure-Begley, A. and Querel, R. (2018), Surface and tropospheric ozone trends in the Southern Hemisphere since 1990: possible linkages to poleward expansion of the Hadley Circulation. Science Bulletin. 
[9] Hu Yongyun, Huang Han, Zhou Chen. Widening and weakening of the Hadley circulation under global warming. Science Bulletin, 2018, 63(10): 640-644. (周天军组织审稿)

[10] DONG JinWei, KUANG WenHui\& LIU JiYuan, 2017. Continuous land cover change monitoring in the remote sensing big data era. SCES, 60(12): 2223-2224. (SCI引用0次, 李新组织审稿)

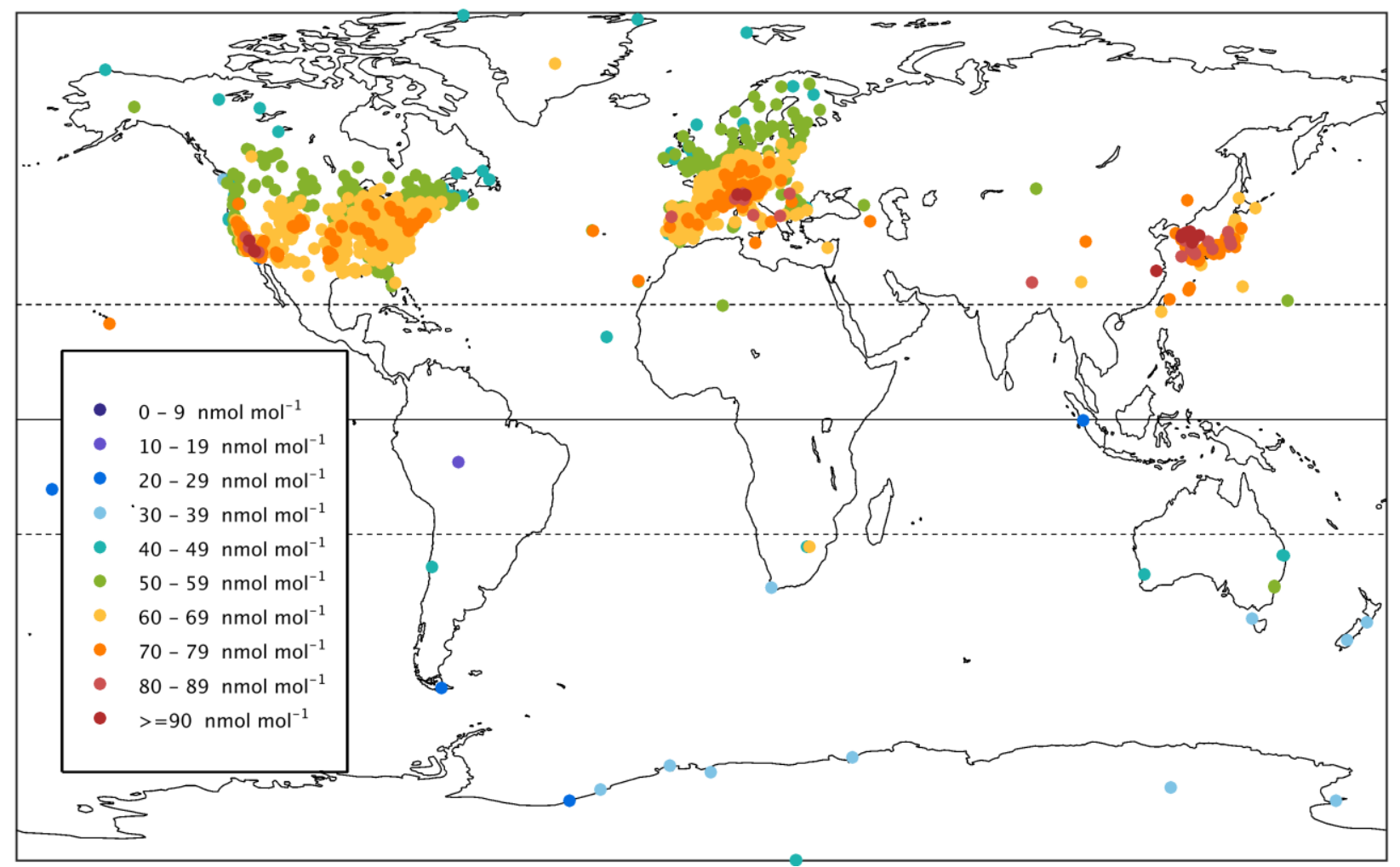

Figure 1. $98^{\text {th }}$ percentile of ozone values at 1185 rural monitoring sites worldwide, focusing on the warm months of April-September in the Northern Hemisphere (1163 monitoring sites) and October-March in the Southern Hemisphere (22 monitoring sites). Data are averaged over the years 2010-2014 with a minimum of three years of data at each site. Figure produced from data provided by the Tropospheric Ozone Assessment Report [1].

\section{Author CV ( $<70$ words)}

Dr. Owen Cooper is a Senior Research Scientist at the University of Colorado Boulder, and works closely with the US National Oceanic and Atmospheric Administration. His interests pertain to: regional and intercontinental transport of atmospheric trace gases; trends in US air quality; global tropospheric ozone trends; stratosphere-troposphere exchange processes. Dr. Cooper presently serves as Chairperson of the International Global Atmospheric Chemistry project's Tropospheric Ozone Assessment Report (TOAR). 